\title{
L-carnitine as an ergogenic aid for patients with chronic obstructive pulmonary disease submitted to whole-body and respiratory muscle training programs
}

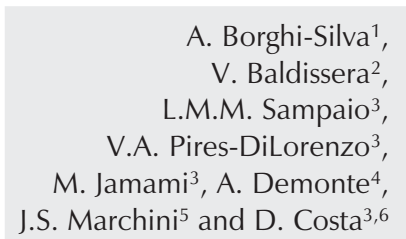

Correspondence

A. Borghi-Silva

Laboratório de Fisioterapia

Cardiovascular

Núcleo de Pesquisas em Exercício

Físico, UFSCar

Rod. Washington Luis, km 235

13565-905 São Carlos, SP

\section{Brasil}

Fax: +55-16-3351-2081

E-mail: audrey@power.ufscar.br

Research supported by FAPESP (No. 00/00311-6) and CNPq. ....................

Received April 12, 2005 Accepted November 29, 2005 ....................

\author{
${ }^{1}$ Laboratório de Fisioterapia Cardiovascular, Núcleo de Pesquisas em Exercício Físico, \\ ${ }^{2}$ Laboratório de Fisiologia do Exercício, Departamento de Ciências Fisiológicas, \\ ${ }^{3}$ Laboratório de Eletromiografia e Espirometria, Universidade Federal de São Carlos, \\ São Carlos, SP, Brasil \\ ${ }^{4}$ Departamento de Alimentos e Nutrição, Universidade Estadual Paulista Júlio de \\ Mesquita Filho, Araraquara, SP, Brasil \\ ${ }^{5}$ Departamento de Clínica Médica, Faculdade de Medicina de Ribeirão Preto, \\ Universidade de São Paulo, Ribeirão Preto, SP, Brasil \\ ${ }^{6}$ Departamento de Fisioterapia, Faculdade de Ciências da Saúde, \\ Universidade Metodista de Piracicaba, Piracicaba, SP, Brasil
}

\section{Abstract}

The effects of adding L-carnitine to a whole-body and respiratory training program were determined in moderate-to-severe chronic obstructive pulmonary disease (COPD) patients. Sixteen COPD patients (66 \pm 7 years) were randomly assigned to L-carnitine (CG) or placebo group (PG) that received either L-carnitine or saline solution ( $2 \mathrm{~g} /$ day, orally) for 6 weeks (forced expiratory volume on first second was $38 \pm 16$ and $36 \pm 12 \%$, respectively). Both groups participated in three weekly 30 -min treadmill and threshold inspiratory muscle training sessions, with 3 sets of 10 loaded inspirations (40\%) at maximal inspiratory pressure. Nutritional status, exercise tolerance on a treadmill and six-minute walking test, blood lactate, heart rate, blood pressure, and respiratory muscle strength were determined as baseline and on day 42. Maximal capacity in the incremental exercise test was significantly improved in both groups $(\mathrm{P}<0.05)$. Blood lactate, blood pressure, oxygen saturation, and heart rate at identical exercise levels were lower in $\mathrm{CG}$ after training $(\mathrm{P}<0.05)$. Inspiratory muscle strength and walking test tolerance were significantly improved in both groups, but the gains of CG were significantly higher than those of PG (40 \pm 14 vs $14 \pm 5 \mathrm{cmH}_{2} \mathrm{O}$, and $87 \pm 30$ vs $34 \pm 29 \mathrm{~m}$, respectively; $\mathrm{P}<0.05$ ). Blood lactate concentration was significantly lower in CG than in PG (1.6 \pm 0.7 vs $2.3 \pm 0.7 \mathrm{mM}, \mathrm{P}<0.05)$. The present data suggest that carnitine can improve exercise tolerance and inspiratory muscle strength in COPD patients, as well as reduce lactate production.
Key words - Chronic obstructive pulmonary disease

- L-carnitine

- Exercise training

- Respiratory muscle training - Blood lactate 


\section{Introduction}

Patients with chronic obstructive pulmonary disease (COPD) are intolerant to exercise mainly due to limited ventilatory capacity (1). This leads to deconditioning, early lactic acidosis, and reduced capillarity and muscle strength (2). An exercise training (ET) program is the main component of pulmonary rehabilitation for COPD patients (3), increasing exercise capacity and reducing dyspnea. Therefore, ET can result in beneficial changes in exercise capacity and has been shown to consistently improve the quality of life of COPD patients (4).

Although training has been shown to be an essential component of the rehabilitation program, patients do not benefit from it to the same extent (5). Indeed, conflictive results concerning lactate reduction and improved physical exercise capacity or muscle strength after training have been reported (6). Patients with reduced exercise capacity who experience less ventilatory limitation for exercise and more reduced respiratory and peripheral muscle strength are more likely to improve their exercise tolerance with a physical training program (5).

In addition to exercise, nutritional factors such as L-carnitine supplementation (7) have been used to improve physical performance. L-carnitine is a quaternary amine whose function has been related to lipid metabolism, sparing muscle glycogen, improving tolerance to physical activity, and reducing muscle fatigue (7). It has also been demonstrated in skeletal and cardiac muscle, in plasma, kidney, liver, and brain.

The importance of the biochemical functions of carnitine in the altered muscle physiology associated with clinical carnitine deficiency supports the critical role of carnitine in muscle bioenergetics (8). In an experimental study, L-carnitine directly improved the fatigue characteristics of muscles enriched in type I fibers when evaluated by the kinetics of contraction and relaxation during a stimulation protocol (9).

In healthy persons, the beneficial effects of long-term treatment with L-carnitine on physical performance cannot be explained by an increase in muscle carnitine stores (10). The effects of supplementation on pathologic conditions that affect exercise performance are less clear. Some studies have shown improvement of exercise performance in patients with cardiovascular (11) and peripheral vascular disease (12). However, to our knowledge, the present study is the first to have been conducted on COPD patients. Thus, the purpose of the present study was to determine whether carnitine supplementation could improve the exercise tolerance, pulmonary function, nutrition, dyspnea, and respiratory muscle strength of COPD patients submitted to a whole-body and respiratory training program.

\section{Patients and Methods}

\section{Subjects}

Volunteers for this study were recruited from COPD outpatients evaluated in the Respiratory Clinic Therapy Unit of UFSCar (São Carlos Federal University) from April 2000 to November 2001. The total number of patients evaluated was 36 , but only 16 satisfied the criteria for the experimental protocol. Patients with primary heart, endocrine, orthopedic, or asthma disorders and those living ten miles or more from the Laboratory were excluded from the study. Stable COPD patients (10 men and 6 women) agreed to participate in the study. All patients were nonsmokers at the time of the study, although all had a cigarette smoking history. Patients had chronic airflow obstruction, defined as measured forced expiratory volume on first second $\left(\mathrm{FEV}_{1}\right)<50 \%$, $\mathrm{FEV}_{1} /$ forced vital capacity $<70 \%$ of percent predicted and a clinical history consistent with COPD. The patients who were taking long-term medication continued to take all 
drugs with no dosage changes. The study protocol was approved by the Ethics Committee for Human Research of the Federal University of São Carlos and all patients gave institutionally reviewed written informed consent to participate in the study.

\section{Experimental design}

Patients were randomly allocated to two groups by drawing lots. The L-carnitine group $(\mathrm{N}=8)$ received a $2 \mathrm{~g} /$ day oral L-carnitine supplementation in two daily doses for 6 weeks, dispensed in 10-mL glass bottles containing $1 \mathrm{~g}$ each, and the control group $(\mathrm{N}=$ 8) received placebo (saline solution, similar in presentation to the L-carnitine preparation) for the same period of time. The supplementation and placebo were similar in color, shape and taste. The patients in each group did not know if they were receiving carnitine supplementation or placebo (singleblind controlled trial). Both groups took part in an exercise and respiratory training program which consisted of medical follow-up by a physician and individual training supervised by physical therapists. L-carnitine was obtained from Sintofarma Laboratory (São Paulo, SP, Brazil). The purity of L-carnitine was evaluated by enzymatic method, and was found to be consistent with the concentrations stated on the labeling (87-90\%).

Lung function tests. All patients underwent spirometry with the determination of $\mathrm{FEV}_{1}$, forced vital capacity and maximal voluntary ventilation according to American Thoracic Society recommendations (13). The values obtained were compared to the predicted normal values of Knudson et al. (14). Spirometry was performed using a Vitalograph ${ }^{\circledR}$ Hand-Held 2120 instrument (Ennis, Ireland), which was calibrated before each test according to manufacturer recommendations using a 1-L syringe.

The maximal respiratory pressures were assessed by maximal inspiratory $\left(\mathrm{PI}_{\max }\right)$ and expiratory pressure $\left(\mathrm{PE}_{\max }\right)$ at residual vol- ume and at total lung capacity, respectively, with an analog pressure gauge according to the method of Black and Hyatt (15). Patients were asked to make maximal inspiratory and expiratory efforts against an obstructed mouthpiece with a small leak to prevent patients from closing their glottis during the maneuver. Patients sustained their maximal effort for one second and the best of three consecutive attempts was used. The predicted values for the Brazilian population reported by Neder et al. (16) were compared with those obtained for patients with COPD.

Body composition. After the patient arrived at the laboratory at 8 am before breakfast, weight and height were measured using a mechanical scale (Welmy, São Paulo, SP, Brazil) and body mass index was calculated. Three consecutive measurements of triceps skinfold (TSF) thickness were used as an indirect estimate of body fat (17). Three measurements of midarm circumference (MAC) were performed in the nondominant arm, positioned parallel to the trunk. A nondistensible tape was placed around the midpoint of the arm without compressing the arm tissue, halfway between the tip of the shoulder (acromial process) and the tip of the elbow (olecranon process). Arm muscle circumference (AMC) was derived from the following formula (18): AMC $(\mathrm{cm})=$ MAC $\pi \times$ TSF $(\mathrm{cm})$.

Caloric intake. A dietitian interviewed each patient and obtained information regarding dietary habits. An estimate of mean daily kilocalorie intake was obtained for each patient by the three-day dietary record. Written instructions for reporting intake, estimating portion sizes and describing mixed dishes were mailed to the patients. Patients were instructed to record all food and beverage consumption for three consecutive days. During the visit, the record was reviewed with the patient and often with the spouse to insure completeness. The diet records were coded for computer nutrient analysis, and mean daily carbohydrate, protein and fat 
intake were estimated using the Nutri ${ }^{\circledR}$ Program (Federal University of São Paulo, UNIFESP-EPM, São Paulo, SP, Brazil) to determine if both groups presented a similar pattern of calorie intake. All patients were instructed to maintain their usual diet during the study.

Exercise capacity. The maximal incremental exercise test was performed on a treadmill (Imbrasport, Milennium ${ }^{\circledR}$ - ATL, Porto Alegre, RS, Brazil). During the test, arterial oxygen saturation was measured by pulse oximetry $\left(\mathrm{SpO}_{2}\right.$; Nonim $8500 A^{\circledR}$, Plymouth, MN, USA), and arterial blood pressure and heart rate (HR) were measured at 2min intervals. HR was measured from the Rto-R interval on the electrocardiogram (TC 500, ECAFIX, São Paulo, SP, Brazil), and arterial blood pressure was measured with a manual sphygmomanometer. At the beginning and at the end of the test the patients were evaluated for possible breathing difficulty (dyspnea) using Borg's CR10 scale (19).

Patients first performed an incremental exercise test that included a 2-min rest period in the sitting position. They began walking at $2.0 \mathrm{~km} / \mathrm{h}$ with a constant $3 \%$ grade, followed by an increase in speed rate of 0.5 $\mathrm{km} / \mathrm{h}$ every 2 min until exhaustion. The test could be interrupted either by the patients, because of dyspnea, leg fatigue or disabling symptoms, or by the investigator, for safety reasons. If $\mathrm{SpO}_{2}$ dropped below $80 \%$ or if threatening signs and symptoms occurred such as electrocardiography alterations and if HR reached the age-predicted maximum, the test could be interrupted. HR reserve was calculated (20) as 100\% - (100 x peak HR)/ (220 - age). The metabolic equivalent (MET) was estimated at peak oxygen consumption $\left(\mathrm{VO}_{2}\right)$ from the following formula (21): $\mathrm{VO}_{2}$ $\left(\mathrm{mL} \mathrm{kg}^{-1} \mathrm{~min}^{-1}\right)=(\mathrm{S} \times 0.1)+(\mathrm{S} \times \mathrm{G} \times 1.8)+$ 3.5 , within a range of intensities from 3.2 to $6.4 \mathrm{~km} / \mathrm{h}$, where: $\mathrm{S}=$ speed in $\mathrm{m} / \mathrm{min}, \mathrm{G}=$ grade in $\%(3 \%=0.03)$ and $1 \mathrm{MET}=3.5$ $\mathrm{mLO}_{2} \mathrm{~kg}^{-1} \mathrm{~min}^{-1}$.
Blood lactate concentration. Blood samples were drawn from each ear lobe. The first drop of blood was discarded to avoid contamination with lactate eliminated through sweat. Blood lactate concentration was measured at rest, every 2 min during the test and 2 min after the end of the maximal exercise test. Each blood sample was collected with a capillary tube previously calibrated with $25 \mu \mathrm{L}$ heparin. After collection, the blood samples were transferred to 2-mL tubes containing $50 \mu \mathrm{L} 1 \%$ sodium fluoride in order to prevent glycolysis. Blood was stored at $-10^{\circ} \mathrm{C}$ for later analysis. Blood lactate concentration was determined by an electroenzymatic method (YSI $1500^{\circledR}$ - Sport Lactate Analyzer, Yellow Springs, OH, USA).

Six-minute walking test (SMWT). Functional exercise performance was measured by the SMWT. This test was performed in a 30-m corridor, and encouragement was standardized (22). To avoid learning effects, the better of two reproducible walks was used on the occasion of the first visit. $\mathrm{SpO}_{2}, \mathrm{HR}$ and Borg's scale were also measured during the test. The test could be interrupted by the patient because of dyspnea and/or leg fatigue. On the occasion of the second visit, the SMWT was performed under the same conditions as used for the pretest. The predicted values of distances walked were compared with those obtained by the patients, according to the 2002 ATS Statement (22).

\section{Exercise training program}

The 6-week ET program was conducted on an outpatient basis. Patients attended 1-h training sessions three times a week. The training intensity was set at walking on a treadmill at $80 \%$ of the maximal speed of the maximal test. Each ET session consisted of 30-min walking exercises on the treadmill and inspiratory muscle training (IMT). During the treadmill walking test, the patient's $\mathrm{HR}$ and $\mathrm{SpO}_{2}$ were continuously monitored. 
Blood pressure was measured before and after each training session. The IMT was performed with a pressure threshold resistive training device. During training, an attempt was made to apply a load corresponding to $40 \%$ of the patient's baseline $\mathrm{PI}_{\max }$ (23). Nose clips were used to occlude nasal airflow. During each session, the patients breathed through an IMT mouthpiece device, with 3 sets of 10 loaded inspirations.

\section{Statistical analysis}

Values are reported as means \pm SD. Due to non-Gaussian distribution and/or inhomogeneity of variance of variable values, nonparametric tests were selected for statistical analysis (24). Thus, the Mann-Whitney and Wilcoxon nonparametric tests were used for intergroup and intragroup comparisons, respectively, with the level of significance set at $\mathrm{P}<0.05$. The gain obtained by the groups was derived from absolute delta comparisons (post-treatment minus pretreatment values).

\section{Results}

Baseline patient characteristics are presented in Table 1. There were no significant differences in age, anthropometry, lung function, protein, fat, or total energy intake between groups. The results of the pulmonary function tests were characterized, on average, by moderate-to-severe airflow obstruction $\left(\mathrm{FEV}_{1}\right.$ around $40 \%$ of the predicted value in both groups). The various procedures were well tolerated by all patients, and no untoward effects of carnitine were reported.

\section{Effects on body composition and dietary intake}

No significant changes were observed in body composition after the exercise training program in either group, as shown in Table
2. There were no significant differences in energy intake of carbohydrates, lipids, protein, or total energy in either group.

\section{Physiological parameters and performance during the incremental test}

Table 3 shows the distance walked in the incremental test on a treadmill, as well as the time and the maximal speed reached. Peak metabolic equivalent obtained before the physical and respiratory program was around 5 METs for both groups. Six weeks of training produced a significant increase in time and speed compared to pretreatment in both groups, and the HR reserve significantly increased $(\mathrm{P}<0.05)$ only in the carnitine group. No significant differences in systolic blood pressure, $\mathrm{SpO}_{2}$, Borg scale, or blood lactate were observed between the two groups when compared at peak speed. A significant increase in HR peak was shown only in the placebo group from absolute delta comparison $(\mathrm{P}<0.05)$. In the incremental exercise test, comparison of responses to identical exercise levels showed that HR, systolic blood pressure and blood lactate concentration were significantly lower, and that $\mathrm{SpO}_{2}$ significantly increased only in the L-car-

Table 1. Characteristics of the patients in the L-carnitine and placebo groups.

\begin{tabular}{|c|c|c|}
\hline & L-carnitine group & Placebo group \\
\hline Age (years) & $69 \pm 9$ & $65 \pm 7$ \\
\hline Weight (kg) & $56 \pm 11$ & $61 \pm 12$ \\
\hline Height $(\mathrm{cm})$ & $160 \pm 1$ & $162 \pm 1$ \\
\hline BMI $\left(\mathrm{kg} / \mathrm{m}^{2}\right)$ & $22 \pm 5$ & $23 \pm 5$ \\
\hline $\mathrm{FEV}_{1}(\mathrm{~L})$ & $0.85 \pm 0.3$ & $0.87 \pm 0.3$ \\
\hline $\mathrm{FVC}(\mathrm{L})$ & $1.69 \pm 0.6$ & $1.63 \pm 0.3$ \\
\hline $\mathrm{FEV}_{1}(\%$ predicted $)$ & $38 \pm 16$ & $36 \pm 12$ \\
\hline Carbohydrate intake $(\%)^{*}$ & $52 \pm 10$ & $46 \pm 6$ \\
\hline Protein intake $(\%)^{*}$ & $15 \pm 3$ & $15 \pm 4$ \\
\hline Fat intake $(\%)^{*}$ & $33 \pm 8$ & $38 \pm 6$ \\
\hline Energy intake $(\mathrm{kcal} / \mathrm{day})^{*}$ & $1832 \pm 452$ & $2077 \pm 401$ \\
\hline
\end{tabular}


nitine group (Table 3). In addition, the reduction in blood lactate concentration was significantly greater for the L-carnitine group $(\mathrm{P}<0.05)$.

Table 2. Effects of L-carnitine supplementation associated with exercise training on body composition and dietary intake.

\begin{tabular}{|c|c|c|c|c|c|c|}
\hline & \multicolumn{3}{|c|}{ L-carnitine group } & \multicolumn{3}{|c|}{ Placebo group } \\
\hline & Pre & Post & $\Delta$ & Pre & Post & $\Delta$ \\
\hline BMI $\left(\mathrm{kg} / \mathrm{m}^{2}\right)$ & $22 \pm 5$ & $21 \pm 4$ & $-1 \pm 1$ & $23 \pm 5$ & $23 \pm 5$ & $0 \pm 1$ \\
\hline $\mathrm{TSF}(\mathrm{mm})$ & $13 \pm 9$ & $12 \pm 6$ & $-1 \pm 3$ & $13 \pm 7$ & $13 \pm 7$ & $1 \pm 2$ \\
\hline MAC (cm) & $25 \pm 4$ & $26 \pm 4$ & $0 \pm 1$ & $27 \pm 4$ & $28 \pm 4$ & $0 \pm 1$ \\
\hline $\mathrm{AMC}(\mathrm{cm})$ & $21 \pm 2$ & $22 \pm 3$ & $1 \pm 1$ & $24 \pm 2$ & $24 \pm 2$ & $1 \pm 4$ \\
\hline Carbohydrate intake (\%)* & $52 \pm 10$ & $52 \pm 7$ & $1 \pm 10$ & $46 \pm 6$ & $48 \pm 6$ & $2 \pm 5$ \\
\hline Protein intake $(\%)^{*}$ & $15 \pm 3$ & $16 \pm 6$ & $1 \pm 6$ & $15 \pm 4$ & $16 \pm 2$ & $1 \pm 3$ \\
\hline Fat intake $(\%)^{*}$ & $33 \pm 8$ & $32 \pm 7$ & $-1 \pm 6$ & $38 \pm 6$ & $36 \pm 5$ & $-3 \pm 5$ \\
\hline Energy intake (kcal/day)* & $1832 \pm 452$ & $1885 \pm 421$ & $88 \pm 317$ & $2077 \pm 401$ & $2066 \pm 337$ & $-29 \pm 168$ \\
\hline
\end{tabular}

Data are reported as mean \pm SD for 8 patients in each group. There were no significant differences between the L-carnitine and placebo groups. BMI = body mass index; TSF = triceps skinfold; MAC = midarm circumference; $\mathrm{AMC}=$ arm muscle circumference; $\Delta=$ absolute delta comparison (post-treatment minus pretreatment values). *Estimated from information provided by the patients.

Table 3. Effect of L-carnitine supplementation associated with exercise training on peak exercise and physiological responses at identical levels of exercise.

\begin{tabular}{|c|c|c|c|c|c|c|}
\hline & \multicolumn{3}{|c|}{ L-carnitine group } & \multicolumn{3}{|c|}{ Placebo group } \\
\hline & Pre & Post & $\Delta$ & Pre & Post & $\Delta$ \\
\hline Peak speed $(\mathrm{km} / \mathrm{h})$ & $5 \pm 1$ & $5.7 \pm 1^{\star \star}$ & $0.7 \pm 0.4$ & $5 \pm 1$ & $5.6 \pm 0.7^{\star}$ & $0.6 \pm 0.5$ \\
\hline Walking distance (m) & $830 \pm 295$ & $1082 \pm 372^{\star \star}$ & $253 \pm 141$ & $831 \pm 328$ & $1027 \pm 290^{*}$ & $196 \pm 186$ \\
\hline Time (min) & $14 \pm 4$ & $16.7 \pm 4^{\star *}$ & $2.8 \pm 1.5$ & $14 \pm 4$ & $16 \pm 3^{*}$ & $2.4 \pm 2.1$ \\
\hline MET & $4.8 \pm 0.7$ & $5.4 \pm 1^{\star \star}$ & $0.6 \pm 0.3$ & $4.8 \pm 0.7$ & $5.2 \pm 0.6^{*}$ & $0.4 \pm 0.4$ \\
\hline $\mathrm{HR}(\mathrm{bpm})$ & $123 \pm 16$ & $122 \pm 20$ & $-1 \pm 6.6$ & $127 \pm 9$ & $138 \pm 8$ & $11 \pm 8^{++}$ \\
\hline HR reserve (\%) & $28 \pm 18$ & $37 \pm 18^{*}$ & $10 \pm 11$ & $27 \pm 13$ & $28 \pm 10$ & $1 \pm 15$ \\
\hline $\mathrm{SBP}(\mathrm{mmHg})$ & $164 \pm 20$ & $157 \pm 12$ & $-7 \pm 13$ & $170 \pm 24$ & $168 \pm 29$ & $-2 \pm 24$ \\
\hline $\mathrm{SpO}_{2}(\%)$ & $86 \pm 5$ & $87 \pm 4$ & $1 \pm 4$ & $87 \pm 7$ & $88 \pm 5$ & $1 \pm 4$ \\
\hline Lactate $(\mathrm{mM} / \mathrm{L})$ & $2.7 \pm 0.9$ & $2.6 \pm 1.6$ & $-0.1 \pm 1$ & $2.6 \pm 1$ & $3.0 \pm 1.3$ & $0.5 \pm 1$ \\
\hline Borg's scale $(0-10)$ & $4 \pm 1$ & $5 \pm 2$ & $0.8 \pm 3$ & $3.8 \pm 1$ & $4.5 \pm 2$ & $0.1 \pm 2$ \\
\hline Same speed $(\mathrm{km} / \mathrm{h})$ & $5 \pm 1$ & $5 \pm 1$ & - & $5 \pm 1$ & $5 \pm 1$ & - \\
\hline $\mathrm{HR}(\mathrm{bpm})$ & $123 \pm 16$ & $114 \pm 16^{*}$ & $-9.5 \pm 8$ & $127 \pm 9$ & $128 \pm 11^{+}$ & $0.2 \pm 13$ \\
\hline $\mathrm{SBP}(\mathrm{mmHg})$ & $164 \pm 20$ & $147 \pm 14^{*}$ & $-17 \pm 18$ & $170 \pm 24$ & $156 \pm 29$ & $-14 \pm 32$ \\
\hline $\mathrm{SpO}_{2}(\%)$ & $86 \pm 5$ & $91 \pm 4^{\star *}$ & $1 \pm 4$ & $87 \pm 7$ & $90 \pm 5$ & $1.5 \pm 4$ \\
\hline Lactate (mM/L) & $2.7 \pm 0.9$ & $1.6 \pm 0.7^{\star *}$ & $-1.1 \pm 0.6$ & $2.6 \pm 1$ & $2.3 \pm 0.7^{+}$ & $-0.3 \pm 0.7^{++}$ \\
\hline Distance on SMWT (m) & $440 \pm 71$ & $527 \pm 77^{\star *}$ & $87 \pm 30$ & $467 \pm 80$ & $501 \pm 74^{*}$ & $34 \pm 29^{++}$ \\
\hline
\end{tabular}

Data are reported as mean \pm SD for 8 patients in each group. Physiological values were compared at peak speed and at identical levels of exercise. MET = metabolic equivalent $\left(3.5 \mathrm{~mL} \mathrm{O}_{2} \mathrm{~kg}^{-1} \mathrm{~min}^{-1}\right) ; \mathrm{HR}=$ heart rate; $\mathrm{SBP}=$ systolic blood pressure; $\mathrm{SpO}_{2}=$ arterial oxygen saturation estimated by pulse oximetry; $\mathrm{SMWT}=$ sixminute walking test; $\Delta=$ absolute delta comparison (post-treatment minus pretreatment values). There were no significant pre-training differences between groups.

${ }^{*} \mathrm{P}<0.05$ compared to pre-training response in placebo and L-carnitine groups (Wilcoxon test). ${ }^{* *} \mathrm{P}<0.01$ compared to pre-training response in L-carnitine group (Wilcoxon test). ${ }^{+}$Significantly different from posttraining response in L-carnitine group (Mann-Whitney test). ${ }^{++}$Significantly different from absolute delta in Lcarnitine group (Mann-Whitney test). 
Performance in the six-minute walking test

No significant differences were observed between groups before training. The L-carnitine group showed a significant improvement in walking distance performance after treatment $(\mathrm{P}<0.01)$, as did the placebo group $(\mathrm{P}<0.05)$. However, the absolute delta in walking distance obtained by the Lcarnitine group was significantly greater $(\mathrm{P}$ $<0.05$ ), as illustrated in Table 3 .

When the predicted values for distance walked were compared with those obtained by our patients, significant reductions $(\mathrm{P}<$ $0.05)$ were observed $(497 \pm 53$ vs $453 \pm 54$ $\mathrm{m}$, respectively).

\section{Maximal respiratory pressure}

No significant differences in maximal respiratory pressure were observed between groups before training. After training, $\mathrm{PI}_{\max }$ increased significantly not only in the Lcarnitine group (from $49 \pm 12$ to $89 \pm 22$ $\mathrm{cmH}_{2} \mathrm{O}$ ) but also in the placebo group (from $54 \pm 19$ to $68 \pm 21 \mathrm{cmH}_{2} \mathrm{O}$ ) with $\mathrm{P}<0.01$. Similar results were obtained for $\mathrm{PE}_{\max }$ in the L-carnitine group (from $66 \pm 18$ to $90 \pm$ $32 \mathrm{cmH}_{2} \mathrm{O}, \mathrm{P}<0.01$ ) and the placebo group (from $69 \pm 26$ to $81 \pm 25 \mathrm{cmH}_{2} \mathrm{O}, \mathrm{P}<0.05$ ). However, the increase in inspiratory muscle strength $\left(\mathrm{PI}_{\max }\right)$ was significantly greater for the L-carnitine group than the placebo group (40 \pm 14 vs $14 \pm 5 \mathrm{cmH}_{2} \mathrm{O}$, respectively, $\mathrm{P}<$ $0.05)$.

When the predicted values were compared to the $\mathrm{PI}_{\max }$ and $\mathrm{PE}_{\max }$ values obtained by patients with COPD $(92 \pm 12$ vs $51 \pm 16$ $\mathrm{cmH}_{2} \mathrm{O}$ for $\mathrm{PI}_{\max }$, and $97 \pm 18$ vs $68 \pm 22$ $\mathrm{cmH}_{2} \mathrm{O}$ for $\mathrm{PE}_{\max }$, respectively), we observed that both values were lower in comparison to healthy subjects of the Brazilian population.

\section{Discussion}

The main results of the present study show the beneficial effects of L-carnitine supplementation in enhancing physiological responses at identical levels of exercise, reducing lactate concentration, improving exercise tolerance and inspiratory muscle strength in COPD.

On the other hand, the supplementation was not associated with modification of the degree of airflow obstruction, improvement of nutritional status or increase in muscle mass. Although TSF and upper arm circumference measurements are extensively used to evaluate body composition, they are not sensitive, especially over short time periods, to detect changes in muscle mass after therapeutic interventions.

In the present study, both groups increased their maximal exercise tolerance. Therefore, the physical training program was efficient in improving the performance of these patients. Our results agree with those obtained by other investigators who reported the importance of physical training in COPD patients (25-27). Previous studies have observed positive effects on maximal exercise capacity with L-carnitine supplementation alone in patients with cardiac insufficiency (11) and peripheral arterial disease (12).

However, patients receiving L-carnitine supplementation demonstrated a greater increment of lactate removal rate. Casaburi et al. (25) showed that ET (without a nutrient supplement) results in significant increases of peak blood lactate concentration and no significant responses to identical exercise levels in the incremental test in COPD patients. Our results showed an expressive reduction in blood lactate concentration at identical exercise levels only in the L-carnitinesupplemented patients.

The literature reports that COPD patients present cardiovascular limitations associated with ventilatory limitation (28). Carnitine has multiple effects on the intermediate metabolism and therefore may be an important factor in cardiac muscle bioenergetics. Some studies have shown the L-carnitine supplementation produces central cardiovascular 
modifications, which contribute to improving exercise performance. L-carnitine supplementation reduced left ventricular size and pulmonary arterial pressure in patients with congestive heart failure (29) and systolic and diastolic blood pressure and ST changes in patients with severe ischemiainduced cardiac insufficiency (11).

In the present study, the L-carnitinesupplemented group showed a significant reduction in HR and systolic blood pressure at submaximal intensities, as well as an increase in HR reserve. These changes are probably explained by the reduction of muscular lactate values (not measured, but lactate was only evaluated in plasma), which permitted a greater utilization of muscle oxygen during physical exercise, delaying the metaboreflex and cardiovascular adjustments. Premature lactic acidosis has been associated with reduced oxidative enzyme concentrations in lower limb muscles, and utilization of the bioactive nutrients involved in muscle energy and substrate metabolism can be of therapeutic importance.

Furthermore, Gosker et al. (30) observed that COPD and chronic heart failure can lead to wasting and weakness of skeletal muscle. These authors showed that patients with severe COPD or chronic heart failure were physically inactive, a fact assumed to have a negative or "detraining" effect on exercise capacity. In our study, we observed lower blood lactate levels, reduced maximal exercise capacity and high HR reserve compared to baseline values in patients with COPD, similar to other authors $(25,30)$. Moreover, the higher HR reserve values demonstrated that patients with COPD were primarily limited by their ventilatory limitation and not by cardiac dysfunction, showing that a possible cardiac impairment was subordinate to pulmonary impairment in the present study.

The subjective sensation of dyspnea was not modified in our patients by L-carnitine supplementation and/or physical training. Similar results have been reported in the literature (31), although some investigators have observed a reduction in dyspnea (32). In our study, the Borg scale was applied only at the beginning and at the high point of exercise both before and after treatment, although it was not applied to the same workload.

Both groups significantly increased their walking distance in the SMWT, indicating increased tolerance to exercise after the program. In a previous study (33), we observed a significant increase of exercise tolerance in the SMWT in patients with mild to moderate COPD receiving L-carnitine supplementation associated with physical exercise. The increased performance of these patients was not associated with an increase of plasma free L-carnitine levels.

Redelmeier et al. (34) reported that an increase of $54 \mathrm{~m}$ in the walking distance in SMWT was thought to be clinically relevant. Thus, we may suggest that physical exercise associated with L-carnitine supplementation was more effective, considering that a mean of $87 \mathrm{~m}$ was obtained compared to physical exercise alone, corresponding to a $34 \mathrm{~m}$ increase. According to some investigators, L-carnitine supplementation (without physical training) can improve the exercise tolerance of patients with peripheral vascular (12) and cardiovascular (11) diseases and of patients submitted to hemodialysis (35).

Respiratory muscle training alone increased the respiratory muscle training of these patients, as also reported by others (36-38). Additionally, L-carnitine supplementation associated with respiratory muscle training significantly increased the inspiratory muscle strength of our patients compared to the placebo group. Our results suggest that IMT associated with L-carnitine supplementation was more effective in increasing respiratory muscle strength than IMT alone. However, no information is currently available on respiratory muscle training associated with L-carnitine. Previous 
studies have observed the effects of L-carnitine supplementation on muscle performance, delayed muscle fatigue in vitro (9), increased workload during an incremental test in healthy subjects (39) and athletes (40), reduced muscle fatigue in hemodialysis patients (35), or improved myocardial performance in congestive heart failure patients (29).

The main limitation of our study was the small number of participants, a fact possibly due to the strict criteria for patient inclusion and the severity of the disease of the patients evaluated. Thus, a study with a larger number of patients would be useful to confirm the present findings. Another limitation of this study was the impossibility of obtaining ventilatory and metabolic measurements due to the high cost of the methodology. Moreover, this study was of the single-blind type, with only the patients being unaware of which medication they were taking since the same researcher controlled the treatment plan, training and administration of L-carnitine or placebo.

The present study demonstrated that Lcarnitine administration adds benefit to exercise and respiratory strength training in outpatients with stable, moderate-to-severe COPD. Larger double-blind and controlled trials are now warranted to confirm these preliminary findings.

\section{Acknowledgments}

L-carnitine was partly supplied by Sintofarma (São Paulo, SP, Brazil) as a donation and additional Sintofarma L-carnitine supplies were funded by FAPESP (No. 00/ 00311-6).

\section{References}

1. Casaburi $R$ (2001). Skeletal muscle dysfunction in chronic obstructive pulmonary disease. Medicine and Science in Sports and Exercise, 33 (Suppl 17): 662-670.

2. Maltais F, LeBlanc $P$, Whittom F et al. (2000). Oxidative enzyme activities of the vastus lateralis muscle and the functional status in patients with chronic obstructive pulmonary disease. Thorax, 55: 848-853.

3. Cooper CB (2001). Exercise in chronic obstructive pulmonary disease: limitation and rehabilitation. Medicine and Science in Sports and Exercise, 33 (Suppl 7): 643-646.

4. Boueri FM, Bucher-Bartelson BL, Glenn KA et al. (2001). Quality of life with a generic instrument (short form -36) improves following pulmonary rehabilitation in patients with chronic obstructive pulmonary disease. Chest, 119: 77-84.

5. Troosters T, Gosselink R \& Decramer M (2001). Exercise training in chronic obstructive pulmonary disease: how to distinguish responders from nonresponders. Journal of Cardiopulmonary Rehabilitation, 21: 10-17.

6. American College of Chest Physicians and American Association of Cardiovascular and Pulmonary Rehabilitation (1997). Pulmonary rehabilitation joint ACCP/ACVPR evidence-based guidelines. Chest, 112: $1363-1396$.

7. Brass EP (2000). Supplemental carnitine and exercise. American Journal of Clinical Nutrition, 72: 618-623.

8. Brass EP \& Hiatt WR (1998). The role of carnitine and carnitine supplementation during exercise in man and in individuals with special needs. Journal of the American College of Nutrition, 17: 207215.

9. Brass EP, Scarrow AM, Ruff LJ et al. (1993). Carnitine delays rat skeletal muscle fatigue in vitro. Journal of Applied Physiology, 75: 1595-1600.

10. Wachter S, Vogt M, Kreis R et al. (2002). Long-term administration of L-carnitine to humans: effect on skeletal muscle carnitine content and physical performance. Clinica Chimica Acta, 318: 51-61.

11. Loster H, Miehe K, Punzel M et al. (2001). Prolonged oral L-carnitine substitution increases bicycle ergometer performance in patients with severe, ischemically induced cardiac insufficiency. Cardiovascular Drugs and Therapy, 13: 537-546.

12. Barker GA, Green S, Askew CD et al. (2001). Effect of propionyl-Lcarnitine on exercise performance in peripheral arterial disease. Medicine and Science in Sports and Exercise, 33: 1415-1422.

13. American Thoracic Society (1991). Lung function testing: selection of reference values and interpretative strategies. American Review of Respiratory Disease, 144: 1202-1218.

14. Knudson RJ, Leibowitz MD \& Holberg CJ (1983). Changes in the normal maximal expiratory flow-volume curve with growth and aging. American Review of Respiratory Disease, 127: 725-734.

15. Black LF \& Hyatt RE (1969). Maximal respiratory pressures: normal values and relationship to age and sex. American Review of Respiratory Disease, 99: 696-702.

16. Neder JA, Andreoni S, Lerario MC et al. (1999). Reference values for lung function tests II. Maximal respiratory pressures and voluntary ventilation. Brazilian Journal of Medical and Biological Research, 32: 719-727.

17. Sahebjami H, Doers JT, Render ML et al. (1993). Anthropometric and pulmonary function test profiles of outpatients with stable chronic obstructive pulmonary disease. American Journal of Medicine, 94: 469-474. 
18. Blackburn GL, Bistrian BR, Mairi MS et al. (1977). Nutritional assessment of the hospitalized patient. Journal of Parenteral and Enteral Nutrition, 1: 1-77.

19. Borg GA (1982). Psychophysical bases of perceived exertion. Medicine and Science in Sports and Exercise, 14: 377-381.

20. Wasserman K, Hansen JE, Sue DY et al. (1994). Principles of Exercise Testing and Interpretation. 2nd edn. Lea \& Febiger, Philadelphia, PA, USA.

21. American College of Sports Medicine (1995). Guidelines for Exercise Testing and Prescription. 5th edn. Lea \& Febiger, Philadelphia, PA, USA.

22. ATS Statement (2002). Guidelines for the Six-Minute Walk Test. American Journal of Respiratory and Critical Care Medicine, 166: 111-117.

23. Nield MA (1999). Inspiratory muscle training protocol using a pressure threshold device: effect on dyspnea in chronic obstructive pulmonary disease. Archives of Physical Medicine and Rehabilitation, 80: 100-102.

24. Zar JH (1984). Biostatistical Analysis. Prentice-Hall, Englewood Cliffs, NJ, USA.

25. Casaburi R, Porszasz J, Burns MR et al. (1997). Physiologic benefits of exercise training in rehabilitation of patients with severe chronic obstructive pulmonary disease. American Journal of Respiratory and Critical Care Medicine, 155: 1541-1551.

26. Maltais F, LeBlanc P, Simard C et al. (1996). Skeletal muscle adaptation to endurance training in patients with COPD. American Journal of Respiratory and Critical Care Medicine, 154: 442-447.

27. Vogiatzis I, Williamson AF, Miles J et al. (1999). Physiological response to moderate exercise workloads in a pulmonary rehabilitation program in patients with varying degrees of airflow obstruction. Chest, 116: 200-207.

28. Sietsema K (2001). Cardiovascular limitations in chronic pulmonary disease. Medicine and Science in Sports and Exercise, 33 (Suppl 7): 656-661.

29. Anand I, Chandrashekhan Y, De Giuli F et al. (1998). Acute and chronic effects of propionyl-L-carnitine on the hemodynamics, exercise capacity, and hormones in patients with congestive heart failure. Cardiovascular Drugs and Therapy, 12: 291-299.

30. Gosker HR, Lencer NHMK, Franssen FME et al. (2003). Striking similarities in systemic factors contributing to decreased exercise capacity in patients with severe chronic heart failure or chronic obstructive pulmonary disease. Chest, 123: 1416-1424.

31. Berry MJ, Adair NE, Sevensky KS et al. (1996). Inspiratory muscle training and whole body reconditioning in chronic obstructive pulmonary disease. American Journal of Respiratory and Critical Care Medicine, 153: 1812-1816.

32. Reardon J, Awad E, Normandin E et al. (1994). The effect of comprehensive outpatient pulmonary rehabilitation on dyspnea. Chest, 105: 1046-1052.

33. Silva AB, Di Lorenzo VAP, Jamami $M$ et al. (2003). Efeitos da suplementação oral de L-carnitina associada ao treinamento físico na tolerância ao exercício de pacientes com doença pulmonar obstrutiva crônica. Jornal de Pneumologia, 29: 379-385.

34. Redelmeier DA, Bayoumi AM, Goldstein RS et al. (1997). Interpreting small differences in functional status: the six-minute walk test in chronic lung disease patients. American Journal of Respiratory and Critical Care Medicine, 155: 1278-1282.

35. Brass EP, Adler S, Sietsema KE et al. (2001). Intravenous L-carnitine increases plasma carnitine, reduces fatigue, and may preserve exercise capacity in hemodialysis patients. American Journal of Kidney Diseases, 37: 1018-1028.

36. Riera HS, Montemayor Rubio TM, Ruiz FO et al. (2001). Inspiratory muscle training in patients with chronic obstructive pulmonary disease: effect on dyspnea, exercise performance, and quality of life. Chest, 120: 748-756.

37. Larson JL, Kim MJ, Sharp JT et al. (1988). Inspiratory muscle training with a pressure threshold breathing device in patients with chronic obstructive pulmonary disease. American Review of Respiratory Disease, 138: 689-696.

38. Preusser BA, Winningham ML \& Clanton T (1994). High- vs lowintensity inspiratory muscle interval training in patients with chronic obstructive pulmonary disease. Chest, 106: 110-117.

39. Vecchiet L, Di Lisa F, Pieralisi G et al. (1985). Influence of Lcarnitine administration on maximal physical exercise. European Journal of Applied Physiology and Occupational Physiology, 54: 131-135.

40. Marconi C, Sassi G, Carpinelli A et al. (1985). Effects of L-carnitine loading on the aerobic and anaerobic performance of endurance athletes. European Journal of Applied Physiology, 54: 131-135. 